\title{
STREAMLINED ASSESSMENT TO ASSIST IN THE DESIGN OF INTERNET-OF-THINGS (IOT) ENABLED PRODUCTS: A CASE STUDY OF THE SMART FRIDGE
}

\author{
Dekoninck, Elies; Barbaccia, Francesca \\ University of Bath
}

\begin{abstract}
This paper shows how designers of IoT-enabled products can assess the environmental impacts associated with the user behaviour and the service system around the product. High-quality secondary data and a user-behaviour survey were able to highlight critical aspects of a smart fridge's design. A streamlined LCA looked at just the in-use phase of the product within 4 PSS scenarios. The system included: the effects on the food waste; grocery shopping methods; fridge door openings; and how the users interact with the smart fridge features. The results show that a smart fridge as within a PSS can reduce the impact on the environment (GWP of 21,700 kg CO2-eq within the 'average PSS scenario' and GWP of 23,100 kg CO2-eq for the normal fridge with 'typical scenario'). The product's increased emissions are counteracted by the reduction in GWP due to: reduction in food waste; and shifts from brick-and-mortar grocery shopping to e-commerce. Therefore some of the critical aspects of the product's design that are most influential on the environmental impact of an IoT fridge are: the design of the web-browsing capability; and the use-by date tracking system.
\end{abstract}

Keywords: (IoT) Enabled Products, Streamlined LCA, Product-Service Systems (PSS), Ecodesign, Case study

Contact:

Dekoninck, Elies

University of Bath

Mechanical Engineering

United Kingdom

e.a.dekoninck@bath.ac.uk

Cite this article: Dekoninck, E., Barbaccia, F. (2019) 'Streamlined Assessment to Assist in the Design of Internet-ofThings (IOT) Enabled Products: A Case Study of the Smart Fridge', in Proceedings of the 22nd International Conference on Engineering Design (ICED19), Delft, The Netherlands, 5-8 August 2019. DOI:10.1017/dsi.2019.379 


\section{INTRODUCTION}

The number of Internet-of-Things (IoT) enabled devices is expected to continue increasing, Statista (2017) predicted that by 2025 there will be 5.44 billion devices connected to the internet. Due to global warming becoming an important and urgent matter which needs addressing and some smart devices promoting a reduction in energy consumption to consumers, it is crucial for designers of IoT enabled products to know whether this is the case. As the environmental impact resulting from the use of these devices needs to be considered during the design phase, the design team will need to start with some kind of life-cycle assessment. This is standard eco-design practice and is described in ISO 14006 (2011). Studying IoT-enabled products to assess the environmental impacts associated with the user behaviour and the service system around the product will enable the identification of critical design aspects. It has been demonstrated by Mishra et al. (2016) and Darby (2017) that there is a lack of studies which examine both the energy consumption of smart devices compared to traditional ones while also incorporating the wider user behavioural change. Chang et al. (2017) stated that a product service system (PSS) allows for the combination of the product and the system and has great advantage to achieve environmental sustainability.

Other authors have identified challenges in assessment approaches for PSS. For example, Kjaer et al. (2016) identify seven challenges when using LCA to evaluate the environmental performance of PSS. A couple of the challenges relevant to our IoT case study are that: user behaviour is affected by the PSS that is being studied (but the data on the behavioural changes is often unavailable); the functional unit and system boundaries are more difficult to define than in conventional product LCA. However, Kjaer et al. (2016) do call for more case studies - such as the one presented in this paper - to help identify methodological challenges.

Environmental assessments of PSS are usually conducted by subject experts (for example, Allais \& Gobert, 2017) whilst there are many situations where non-experts - such as design team members would benefit from being able to conduct a streamlined assessment. Streamlining the analysis allows for the process to be more manageable by limiting the scope and using qualitative and quantitative approaches - a combination of the two is required for a non-expert to evaluate impacts. Therefore, the overarching aim of this study was to present a streamlined assessment case study which shows how designers of IoT-enabled products can assess the environmental impacts associated with the user behaviour and the service system around the product. This study shows how approaches like these can lead to the identification of critical aspects of the product's design by streamlining, even if not as detailed as a full LCA conducted by an expert.

\section{METHODOLOGY}

Whilst other authors are exploring the use of tools such as System Dynamics (Lee et al., 2012) to assess the environmental impact of product service systems, Life Cycle Assessment (LCA) is still the most established and was therefore selected as the most appropriate way to examine the impact of the devices. LCA is an environmental management tool which quantifies the environmental strain of a product over its entire life - with a PSS created to look at the wider system affected. In their most recent paper, Kjaer et al. (2018), provide six guidelines to support PSS evaluation. Their work sets out to inspire more quantitative studies which evaluate the actual changes caused by a PSS and identify which circumstances of the PSS lead to environmental improvements. The most important guideline for this study looking at IoT-enabled products was to focus on scenario-approach and qualitative learnings, and especially to focus on the processes that have the largest influence on the results, allowing for uncertainty in data precision and multiple scenario assessments.

In order to present a streamlined environmental assessment of an IoT-enabled product - to be conducted by a non-expert designer - the case study of the fridge was selected as an appropriate example. Here an IoT-enabled fridge (smart fridge) is compared to a non-enabled fridge (normal fridge). Using the European Commission report (European Commission (EC), 2009) and the top 20 best-selling fridges in the UK market (John Lewis online, 2018), the normal fridge was defined as a single door fridge-freezer model, with an average capacity of 275 L. The smart fridge was based on the Samsung Family Hub Smart Freestanding Fridge Freezer as this was the fridge with the most advanced technology currently available. The single door model with a $356 \mathrm{~L}$ capacity was selected to better represent the UK market. 
Compared to the normal fridge the Family Hub has the additional smart technology of a 21.5" touchscreen monitor, three internal cameras and $5 \mathrm{~W}$ speakers. These allow the user to order groceries through the screen on the fridge door, to track use-by dates of products placed inside the fridge, to view the contents of the fridge both from the closed fridge door and remotely using the app and to use the screen for entertainment purposed such as watching videos or browsing the internet.

A streamlined LCA was completed in this study concentrating on solely the in-use phase of the product, as this is where the highest environmental impact of fridges occurs. The Commission of the European Communities (European Commission (EC), 2009) and the Japan Electrical Manufacturers' Association (JEMA, 2014) found that the use phase of a household fridge is accountable for $72 \%$ and $82 \%$ of the environmental impact respectively. The PSS of the fridge allowed for the user behaviour to be included in the study, covering the whole system: the impact of the product itself (the fridge) plus the impact of any additional smart features; completing the grocery shopping trips; loading the groceries into the fridge; using the cameras to see inside the fridge; the amount of food wasted; and opening of the fridge door. The environmental impact is quantified in terms of Global Warming Potential (GWP) over a 100-year period. GWP quantifies how much heat a greenhouse gas traps in the atmosphere and as a result increases the temperature of the Earth.

\subsection{Data collection and review}

A systematic literature review process was used to collect the data required to carry out the analysis and extrapolate the required results from already existing LCA studies. To do so the method used by Clune et al. (2017) based on PRISMA Statement protocol was followed to reduce the risk of bias.

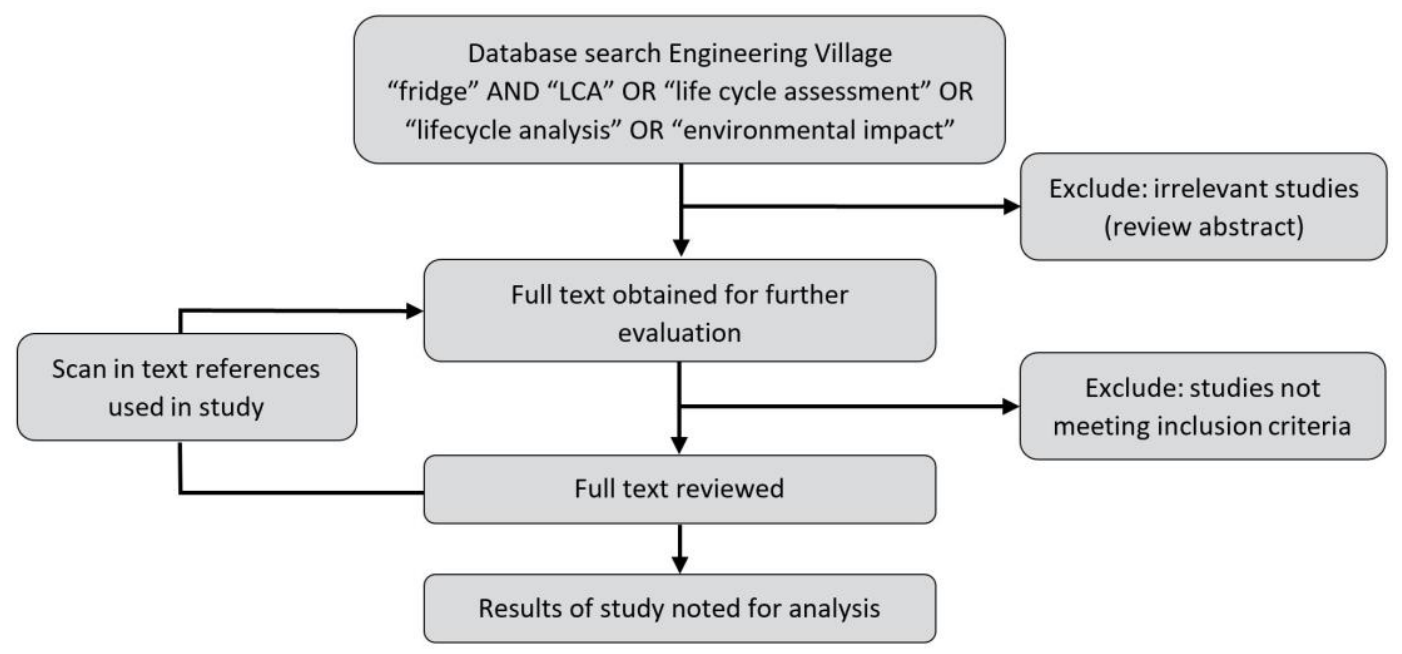

Figure 1. Adaptation of systematic review process used by Clune et al. (2017)

The review of the literature was completed in March 2018. Potentially useful studies were selected in two stages. Firstly, concentrating solely peer-reviewed journals or conference proceedings to ensure the data and findings presented were reliable. These were then narrowed down by applicability to the study. Therefore, only studies which disclosed results for GWP in CO2-eq per unit mass or a comparable category, system boundary and functional unit used were included. Studies which gave results as percentages, non-translatable impact categories to GWP and where the in-use phase could not be isolated were excluded. To allow an average figure to be calculated for the LCA of every aspect covered each study had its result converted to $\mathrm{kg} \mathrm{CO} 2$-eq for an equal functional unit and system boundary.

\section{PRODUCT DATA}

LCA data for the use phase was collected for each of the components used in the normal and smart fridge. This included the fridge itself, the LCD screen, the cameras, the speakers, any additional sensors and the network connection. This was done following the Methodology described in section 2.

\subsection{Fridge}

The impact of the fridge was calculated following a detailed literature review on all LCA studies found. From this the five most relevant studies were selected, an overview of these is described in Table 1. 
Table 1. Results gathered from existing LCA studies of fridges

\begin{tabular}{|l|c|c|c|c|c|c|}
\hline Source & $\begin{array}{c}\text { Year of } \\
\text { Study }\end{array}$ & $\begin{array}{c}\text { Volume } \\
(\mathrm{L})\end{array}$ & $\begin{array}{c}\text { Years } \\
\text { in use }\end{array}$ & Geography & Unit & GWP (unit) \\
\hline $\begin{array}{l}\text { European Commission } \\
(2009)\end{array}$ & 2009 & 294 & 1 & Europe & $\begin{array}{c}232 \text { million } \\
\text { fridge-freezers }\end{array}$ & $\begin{array}{c}48 \\
\text { (Mt CO2-eq) }\end{array}$ \\
\hline $\begin{array}{l}\text { European Commission } \\
(2009)\end{array}$ & 2009 & 230 & 1 & Europe & $\begin{array}{c}75 \text { million } \\
\text { freezers }\end{array}$ & $\begin{array}{c}14 \\
\text { (Mt CO2-eq) }\end{array}$ \\
\hline JEMA, (2014) & 2010 & 500 & 10.4 & Japan & 1 fridge-freezer & $\begin{array}{c}1382 \\
\text { (kg of CO2) }\end{array}$ \\
\hline Xiao et al. (2015) & 2015 & 200 & 10 & China & 1 fridge & $\begin{array}{c}1670 \\
\text { (kg CO2-eq) }\end{array}$ \\
\hline Monfared et al. (2014) & 2014 & 223 & 14 & Europe & 1 fridge & $\begin{array}{c}526 \\
\text { (kg CO2-eq) }\end{array}$ \\
\hline
\end{tabular}

To convert all the values to a comparable unit they were first converted to the equivalent GWP had they been manufactured in 2017 resulting a study by Waters (2015). Followed by a conversion had the fridges been used in the UK in 2017; using the study by Brander et al. (2011) for variation between countries and GOV.UK. (2017) for yearly emission factors variations. Lastly, all units were converted to the impact they would have had, had they all been fridge-freezers. This was done through analysis comparing only fridge and only freezer models compared to fridge-freezer models using the top 20 best-selling products in the UK market (John Lewis online, 2018). Following the data manipulation to a comparable value the average GWP per litre per year per unit, if manufactured and used in the UK in 2017 as a fridge-freezer model was $0.42 \mathrm{~kg} \mathrm{CO} 2$-eq.

\subsection{Screen}

When collecting data for the impact of the screen it was decided to concentrate on LED LCD screens as this is the newer technology currently used in the market. The research was based around desktops and televisions as these have direct electricity connection as the fridge screen, looking for touchscreen models if possible. Using the studies by Bhakar et al. (2015) and Schafer (2015) it was calculated that the GWP of an LED LCD screen of 21.5" results in an environmental impact of $0.0085 \mathrm{~kg} \mathrm{CO} 2$-eq per hour in use. The study by Socolof et al. (2005) was also considered, however disregarded due to the year it was published and lack of indication on the type of LCD technology used.

\subsection{Cameras, speakers \& sensors}

The Samsung Family Hub product fiche (Samsung, 2017) states the speakers to be 5 W. As no LCA studies stating the environmental impact of speakers could be found, it was calculated following the assumption that the impact of the in-use phase of electrical devices arises mainly from the electricity consumption. Using the GHG emission conversion factors released by GOV.UK (2017) the GWP for the speakers was calculated to be $0.0046 \mathrm{~kg} \mathrm{CO} 2$-eq per hour in use.

A similar process was used to calculate the GWP of the cameras. These were assumed to have the same power consumption as the Nest Cam, 7-9 W when in use, as both are connected to the internet. Which resulted in a GWP of $0.000021 \mathrm{~kg} \mathrm{CO} 2$-eq per photo.

Finally following the literature review on data for the impact of the sensors, these were found to have a negligible impact when looking at solely the in-use phase for the type of sensors used in the fridge. The studies used to come to this conclusion were those by Bonvoisin et al. (2012, 2014 and 2011) and Louis et al., 2015).

\subsection{Network connection}

Studies by Malmodin et al. (2010, 2012 and 2014) and Shehabi et al. (2014) were used to find the impact of the network connection, for both the use of the smartphone app in the store and the fridge connection in the home. The 'Life Cycle Assessment of ICT - Supporting Information' (Malmodin et al., 2014) paper was selected as this covered the whole network trajectory required. From this it was found that the GWP of internet use by a fixed connection was $1.48 \mathrm{~kg} \mathrm{CO} 2-\mathrm{eg} / \mathrm{GB}$, while the mobile (3G) connection had an impact of $2.77 \mathrm{~kg} \mathrm{CO} 2-\mathrm{eg} / \mathrm{GB}$. Table 2 shows the results gathered for the 
amount of GB used per hour for the features available, which are later used to quantify the impact of the network usage in terms of GWP once the use scenarios were established.

Table 2. GB used per hour of use split by different types of service used

\begin{tabular}{|l|c|}
\hline Service Used & Data Use $(\mathrm{GB} / \mathrm{hr})$ \\
\hline Stream video & 0.6 \\
\hline Game online & 0.04 \\
\hline Stream music & 0.12 \\
\hline Internet browse & 0.6 \\
\hline App use & 0.4 \\
\hline
\end{tabular}

\section{SYSTEM DATA}

When looking at the wider system affected by the fridge it was decided to concentrate on the GWP of four main aspects following an understanding of the capabilities offered by the smart fridge: the amount of food wasted, the method in which the grocery shopping was completed; the number of fridge door openings and the user behaviour in relation to the smart features available on the fridge.

\subsection{Food waste}

When taking into consideration the impact of the food waste it was assumed that each item of produce which was discarded due to going past its use-by date would be replaced by the same exact product. There are numerous studies looking at the LCA of specific food produce and dietary patterns (e.g. Clune et al., 2017; Winkler et al., 2016; Kramer et al., 1999; Lesschen et al., 2011; Notarnicola et al., 2017; Veeramani et al., 2017) based in the required geographical location and completed relatively recently. The most applicable of which to calculate the impact of food waste was that by Notarnicola et al. (2017) to understand the average consumption of a European citizen, while that by Clune et al. (2017) was used to calculate the impact of each food group. A study by Wrap (2015) was found to state that $20 \%$ of all food is wasted in a domestic sector, as no study was found showing the waste split by each food group, this was taken as an average across all. From these studies, it was found that on average a person in the EU creates a GWP of $271 \mathrm{~kg} \mathrm{CO} 2$-eq per year through food waste, if all products wasted are assumed to be replaced with identical produce.

This did not cover the GWP created by waste management as this figure could not be found in terms which could be applied to the study.

Moreover, a study by Statista (2018) found that in the UK 60\% of all food waste is avoidable, while $18 \%$ is possibly avoidable. Avoidable food waste is classified as produce, which is disposed as it has gone past its best, while possibly avoidable food waste is food that some people eat while others do not, such as bread crusts. For the purpose of this study the $60 \%$ avoidable figure was used.

\subsection{Grocery shopping}

The two main methods of completing a grocery shopping trip are for the consumer to travel to the supermarket or have their groceries delivered. Several studies examined the impact of these two types of shopping for non-perishable products and single item purchases such as books (Matthews et al., 2011) toys (Winkler et al., 2013) and electronic products (Weber et al., 2009, Pålsson et al., 2017). However, only that by Van Loon et al. (2015) was found to compare the impact of the two methods when looking at grocery shopping specifically. Here the traditional way of shopping, that of brick \& mortar, created a GWP of $7.2 \mathrm{~kg} \mathrm{CO} 2$-eq per trip. Compared to a GWP of $5.1 \mathrm{~kg} \mathrm{CO} 2$-eq per delivery when looking at the online grocery fulfilment method. To ensure accuracy, this was compared to the values quoted by Ocado (2018) of $5.22 \mathrm{~kg} \mathrm{CO} 2$-eq per delivery.

\subsection{Door openings}

Elias' research (2011) on user-efficient design, examines the additional electricity consumption of opening the fridge door. Using this study and the conversion rates between electricity use and GWP provided by GOV.UK (2017) it was possible to calculate the additional GWP from opening the fridge door. On average a fridge door is opened 172 times per week, the loading of groceries makes up $28 \%$ of these, creating an additional GWP of $3.69 \mathrm{~kg}$ CO2-eq. 


\subsection{User behaviour}

To understand how the Family Hub users interacted with the smart features, surveys of Samsung smart fridge owners as well as product reviews written by smart fridge owners were used - this was done due to a limited number of responses from the surveys. Therefore, the survey results shown in Table 3 were used to create the 'average' scenario, reinforced by the reviews. While the hypothetical 'most' scenario was created by assuming maximum use of the smart features as understood from the reviews.

Table 3. Results gathered from use of Family Hub survey

\begin{tabular}{|l|c|c|c|}
\hline Smart Feature & Frequency (per week) & Time (minutes per session) & Source \\
\hline Look inside using screen & 10 & N/A & Survey \& Reviews \\
\hline Look inside remotely & 3 & N/A & Survey \& Reviews \\
\hline Grocery shopping & 0.2 & N/A & Survey \& Reviews \\
\hline Videos & 2 & 35 & Survey \& Reviews \\
\hline Music & 4 & 45 & Survey \& Reviews \\
\hline Draw & 1 & N/A & Survey \& Reviews \\
\hline Browse internet & 3 & N/A & Lit Review \\
\hline
\end{tabular}

\section{ANALYSIS}

\subsection{Lifetime of the product}

The lifetime of the product used for the analysis was based on the average lifetime of the fridge as this is the main component in question. It was decided to follow the Commission of the European Communities report with a lifespan of 15 years for the fridge. The study includes a detailed preparatory report which describes that the data used to calculate the economic variables used as inputs was gathered from reliable studies, such as GfK, and adjustment from lessons learnt through previous studies included (European Commission, 2005/32/EC).

\subsection{Scenarios to be analysed}

In this study different scenarios relating to the use of both the normal and smart fridge were analysed and a PSS was created for each based on the data described in section 4.

- Normal fridge - use of a normal fridge with wider system following that expected of an average UK household.

- Smart fridge 'least' - use of smart fridge with wider system following that of a normal fridge, additional smart technology not used by household.

- Smart fridge 'average' - use of smart fridge with wider system following that of an average smart fridge use, quantified using the surveys and reviews of the Samsung Family Hub.

- Smart fridge 'most' - hypothetical use of smart fridge with wider system following that of using a smart fridge to a maximum but realistic amount, assumed scenario created through understanding the user behaviour and the full potential of the product.

\subsection{Comparison of PSS of different scenarios}

For each scenario described the impact of each part of the system was calculated following the results found in sections 3 and 4. From this an overall environmental impact in terms of GWP was found, the results of which are shown in Table 4. Here it can be seen that to minimise the GWP of the domestic fridge the smart fridge 'most' scenario would be preferred, creating a GWP of 20,200 kg CO2-eq over the 15 year in-use lifetime of the fridge. While the normal fridge scaled to $387 \mathrm{~L}$ and the smart fridge 'least' scenario create the largest impact with $23,100 \mathrm{~kg} \mathrm{CO} 2$-eq and $23,200 \mathrm{~kg} \mathrm{CO} 2$-eq respectively. The smart fridge 'average' scenario was calculated to have an impact of 21,700 kg CO2-eq, so lower than the normal fridge. 
Table 4. Comparison of the PSS results for each of the fridge scenarios (totals may not add up due to rounding of figures)

\begin{tabular}{|l|c|c|c|c|c|}
\hline System Stage & $\begin{array}{c}\text { Normal Fridge } \\
\text { (European Commission, } \\
2005 / 32 / E C) . \text { (Original) }\end{array}$ & $\begin{array}{c}\text { Normal } \\
\text { Fridge } \\
(387 \mathrm{~L})\end{array}$ & $\begin{array}{c}\text { Smart } \\
\text { Fridge } \\
\text { 'Least' }\end{array}$ & $\begin{array}{c}\text { Smart } \\
\text { Fridge } \\
\text { 'Average' }\end{array}$ & $\begin{array}{c}\text { Smart } \\
\text { Fridge } \\
\text { 'Most' }\end{array}$ \\
\hline Product use & 1700 & 2400 & 2500 & 4200 & 8000 \\
\hline Fridge & 1700 & 2438 & 2438 & 2438 & 2438 \\
\hline Screen & - & - & 39 & 72 & 132 \\
\hline Cameras & - & - & 3 & 3 & 2 \\
\hline Speakers & - & - & - & 16 & 44 \\
\hline Internet & - & - & - & 1657 & 5396 \\
\hline Grocery shopping & 10700 & 10700 & 10700 & 10300 & 7600 \\
\hline Brick \& mortar & 10700 & 10700 & 10700 & 9400 & - \\
\hline Online (delivery) & - & - & - & 920 & 7600 \\
\hline Loading groceries into fridge & 55 & 55 & 55 & 55 & 55 \\
\hline Use of app & 0 & 0 & 0 & 220 & 500 \\
\hline Food wasted & 9800 & 9800 & 9800 & 6800 & 3900 \\
\hline Opening door during week & 140 & 140 & 140 & 130 & 110 \\
\hline Total & 22400 & 23100 & 23200 & 21700 & 20200 \\
\hline
\end{tabular}

\section{DISCUSSION}

The main contributor for the increase in GWP of the product was found to be due to the internet connection. This increased the GWP of the smart fridge 'average' scenario by 1,600 kg CO2-eq compared to the normal scaled-up fridge. However, when taking into consideration the whole PSS of the fridges; the grocery shopping fulfilment method shifting from in-store to online and decrease in food waste meant that the overall GWP of the smart fridge was lower than that of the normal fridge. The use of the screen did reduce the amount of fridge door openings for browsing. However, this was still found to be responsible for only $20 \%$ of all door openings as to move products physically the door needed to be opened.

\subsection{Uncertainty and limitations}

One of the main uncertainties with this study is that the tasks performed on the fridge would be replacing those which would have otherwise been done using other devices. For example, if 50\% of the internet usage through the fridge is additional (would have not been completed had it not been for the fridge) the GWP of the smart fridge 'average' scenario would decrease to $19,900 \mathrm{~kg} \mathrm{CO} 2$-eq, lower than the 21,700 $\mathrm{kg} \mathrm{CO} 2$-eq the value calculated. Such a finding could have implications for the designer. For example, if the browsing capability of the device is designed to deliver a conventional browsing experience to the user, one could argue, that the internet usage is more likely to be replacing other internet usage.

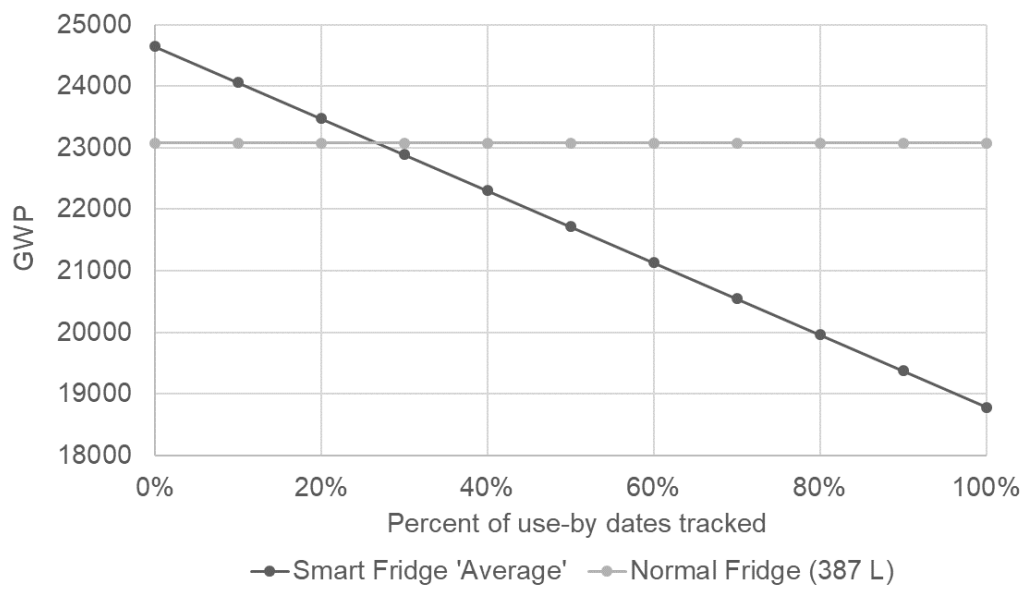

Figure 2. Variation to GWP for amount of use-by dates tracked 
Another major assumption which was taken was that $50 \%$ of the use-by dates were recorded for the smart fridge 'average' scenario, the effect this has on the overall GWP is shown in Figure 2. If less than $30 \%$ are tracked then the GWP of the smart fridge becomes larger than that of the normal fridge. However, as the last phase of the food lifecycle is not included in this study this value is expected to be lower. The implications for the designer here are about the design of the user interface of the use-by date tracking system. This would need to be designed carefully to really alter user behaviour and ultimately reduce food waste.

One of the main limitations of the study is believed to arise from concentrating on solely the in-use phase of the product: all other stages of the lifecycle of the fridge, such as manufacturing and disposal were disregarded. This is especially true for the LCD screen, as only $60 \%$ of the overall GWP arises in the in-use phase and the rest from manufacturing (Hischier \& Wäge, 2015), and the sensors which show negligible impact in the in-use phase but not in the rest of the lifecycle.

The aim of this study was to present a streamlined assessment case study, which shows how designers of IoT-enabled products can assess the environmental impacts associated with the user behaviour and the service system around the product. The study was able to use secondary LCA data and collect some primary user behaviour data to deliver a scenario-based streamlined LCA assessment of this PSS. The findings are interesting for the design of IoT-enabled products in general, as well as showing how non-experts might tackle the assessment prior to the design.

\section{CONCLUSION}

Findings concerning the case study of the smart fridge itself, showed that the wider system benefits achieved through the use of the smart device outweigh the added environmental impact due to increased energy consumption of the device. The analysis of the wider system affected by the fridge allowed for the inclusion of user behaviour. To compare the PSS of the smart and normal fridge four possible scenarios were created; the normal fridge, the smart fridge 'least' scenario, the smart fridge 'average' scenario and the smart fridge 'most' scenario. It was found that the smart fridge would only be beneficial, in terms of environmental impact, if at least $30 \%$ of the use-by dates of the products placed inside the fridge were tracked. This case study shows that it may be possible to design

IoT-enabled devices to offset the increased environmental impacts associated with the additional technology, if the new functionalities are designed to reduce overall environmental impacts at higher system levels - in this case, at the household level. In earlier work, we used the results from similar streamlined assessment to inform user-centred eco-design of a conventional fridge (Elias, 2011), and with the subsequent collection of real data from a re-designed fridge, we showed significant changes in user behaviour and energy consumption. Several social scientists are currently studying behaviour and food waste in order to understand relations between food waste and behavioural changes (Stancu et al., 2016; Graham-Rowe et al., 2015; and Quested et al., 2013).

Some of the critical aspects of the product's design that are influential for the environmental impact of an IoT fridge are: the design of the web-browsing capability which can cause additional household impacts related to Internet use; and the use-by date tracking system which has the potential to reduce food waste. Since these are the critical features, what any company aiming to design an environmentally-friendly IoT fridge would need to do is to understand: how the Internet browsing feature can be used to replace other browsing rather than creating additional browsing for the household; how the Internet browsing feature could reduce other impacts like 'shopping miles' by enabling more efficient delivery-based shopping; and how the use-by-date tracking system can to be designed to change user behaviour around food stocking and cooking in order to ultimately reduce food waste.

The streamlined LCA method used showed that, a non-expert was able to draw detailed conclusions by: using Clune et al. (2017) structure to ensure the best-available secondary LCA data was used; using a scenario-based approach to analyse the PSS; and by focusing on the aspects of the PSS that have the largest influence on the results (the use-stage of the product's life-cycle).

\section{REFERENCES}

Allais, R. and Gobert, J. (2017), "Environmental assessment of PSS, feedback on 2 years of experimentation", Matériaux \& Techniques, Vol. 105 No. 5-6, pp. 504.

Bhakar, V., Agur, A., Digalwar, A.K. and Sangwan, K.S. (2015), "Life cycle assessment of CRT, LCD and LED monitors", Procedia CIRP, Vol. 29, pp. 432-437. 
Bonvoisin, J., Lelah, A., Mathieux, F. and Brissaud, D. (2011), "Environmental impact assessment model for wireless sensor networks”, Glocalized Solutions for Sustainability in Manufacturing, pp. 124-129.

Bonvoisin, J., Lelah, A., Mathieux, F. and Brissaud, D. (2012), “An environmental assessment method for wireless sensor networks", Journal of Cleaner Production, Vol. 33, pp. 145-154.

Bonvoisin, J., Lelah, A., Mathieux, F. and Brissaud, D. (2014), "An integrated method for environmental assessment and ecodesign of ICT-based optimization services”, Journal of cleaner production, Vol. 68, pp. 144-154.

Brander, M., Sood, A., Wylie, C., Haughton, A. and Lovell, J. (2011), “Technical Paper”, Electricity-specific emission factors for grid electricity, Ecometrica, Emissionfactors. com.

BS Standard ISO 14006: 2011 2011. Environmental Management Systems-Guidelines for Incorporating Ecodesign.

Chang, F., Zhou, G. and Lu, Q. (2017), “A mapping network model integrating service to warrant function availability of complex electro-mechanical products", Procedia CIRP, Vol. 61, pp. 667-672.

Clune, S., Crossin, E. and Verghese, K. (2017), "Systematic review of greenhouse gas emissions for different fresh food categories", Journal of Cleaner Production, Vol. 140, pp. 766-783.

Commission of the European Communities (2009), PROPOSAL FOR A COMMISSION REGULATION implementing Directive 2005/32/EC with regard to household refrigerating appliances FULL IMPACT ASSESSMENT,", Brussels.

Commission of the European Communities (2009), Commission Staff Working Document - Commission Regulation implementing Directive 2005/32/EC with regard to ecodesign requirements for simple set-top boxes, Belgium.

Darby, S.J. (2018), "Smart technology in the home: time for more clarity", Building Research \& Information, Vol. 46 No. 1, pp. 140-147.

Elias, E.W.A. (2011), User - Efficient Design : Improving the Energy Efficiency of User Behaviour A Behaviour Design Case Study: The Domestic Refrigerator, PhD Thesis, Bath.

GOV.UK 2017, Government emission conversion factors for greenhouse gas company reporting.

Graham-Rowe, E., Jessop, D.C. and Sparks, P. (2015), "Predicting household food waste reduction using an extended theory of planned behaviour", Resources, Conservation and Recycling, Vol. 101, pp. 194-202.

Hischier, R. and Wäger, P.A. (2015), “The transition from desktop computers to tablets: A model for increasing resource efficiency?", ICT Innovations for Sustainability, Springer, Cham, pp. 243-256.

Lewis, J. (2018), John Lewis Web Site. [Online]. Available: https://www.johnlewis.com/. [Accessed: 15-Apr-2018].

Kjaer, L.L., Pagoropoulos, A., Schmidt, J.H. and McAloone, T.C. (2016), "Challenges when evaluating product/service-systems through life cycle assessment", Journal of Cleaner Production, Vol. 120, pp. 95-104.

Kramer, K.J., Moll, H.C., Nonhebel, S. and Wilting, H.C. (1999), "Greenhouse gas emissions related to Dutch food consumption", Energy Policy, Vol. 27 No. 4, pp. 203-216.

Lee, S., Geum, Y., Lee, H. and Park, Y. (2012), "Dynamic and multidimensional measurement of productservice system (PSS) sustainability: a triple bottom line (TBL)-based system dynamics approach", Journal of Cleaner Production, Vol. 32, pp. 173-182.

Lesschen, J.P., Van den Berg, M., Westhoek, H.J., Witzke, H.P. and and Oenema, O. (2011), “Greenhouse gas emission profiles of European livestock sectors", Animal Feed Science and Technology, Vol. 166, pp. 16-28.

Louis, J.N., Calo, A., Leiviskä, K. and Pongrácz, E. (2015), “Environmental impacts and benefits of smart home automation: life cycle assessment of home energy management system”, IFAC-PapersOnLine, Vol. 48 No. 1, pp. 880-885.

Malmodin, J., Lundén, D., Moberg, Å, Andersson, G. and Nilsson, M. (2014), "Life cycle assessment of ICT: Carbon footprint and operational electricity use from the operator, national, and subscriber perspective in Sweden", Journal of Industrial Ecology, Vol. 18 No. 6, pp. 829-845.

Malmodin, J., Lundén, D., Nilsson, M. and Andersson, G. (2012, September), "LCA of data transmission and IP core networks", Electronics Goes Green 2012+(EGG), IEEE, pp. 1-6.

Malmodin, J., Moberg, Å, Lundén, D., Finnveden, G. and Lövehagen, N. (2010), “Greenhouse gas emissions and operational electricity use in the ICT and entertainment \& media sectors", Journal of Industrial Ecology, Vol. 14 No. 5, pp. 770-790.

Matthews, H., Hendrickson, C. and Soh, D. (2001), "Environmental and economic effects of e-commerce: A case study of book publishing and retail logistics", Transportation Research Record: Journal of the Transportation Research Board No. 1763, pp. 6-12.

Mishra, D., Gunasekaran, A., Childe, S.J., Papadopoulos, T., Dubey, R. and Wamba, S. (2016), "Vision, applications and future challenges of Internet of Things: A bibliometric study of the recent literature", Industrial Management \& Data Systems, Vol. 116 No. 7, pp. 1331-1355.

Monfared, B., Furberg, R. and Palm, B. (2014), "Magnetic vs. vapor-compression household refrigerators: a preliminary comparative life cycle assessment", International journal of refrigeration, Vol. 42, pp. 69-76.

Notarnicola, B., Tassielli, G., Renzulli, P.A., Castellani, V. and Sala, S. (2017), "Environmental impacts of food consumption in Europe", Journal of cleaner production, Vol. 140, pp. 753-765.

Ocado (2018), Ocado Corporate Responsibility Report 2018, Hatfield. 
Pålsson, H., Pettersson, F. and Hiselius, L.W. (2017), "Energy consumption in e-commerce versus conventional trade channels-Insights into packaging, the last mile, unsold products and product returns", Journal of cleaner production, Vol. 164, pp. 765-778.

Quested, T.E., Marsh, E., Stunell, D. and Parry, A.D. (2013), "Spaghetti soup: The complex world of food waste behaviours. Resources", Conservation and Recycling, Vol. 79, pp. 43-51.

Samsung. Family HubTM Fridge Freezer, 380L, 2017. [Online]. Available: http://www.samsung.com/uk/support/model/RB38M7998S4/EU/. [Accessed: 28-Mar-2018].

Schafer, S. (2015), Carbon Footprint of Dell OptiPlex 3030.

Shehabi, A., Walker, B. and Masanet, E. (2014), "The energy and greenhouse-gas implications of internet video streaming in the United States”, Environmental Research Letters, Vol. 9 No. 5, pp. 054007.

Socolof, M.L., Overly, J.G. and Geibig, J.R. (2005), "Environmental life-cycle impacts of CRT and LCD desktop computer displays", Journal of Cleaner production, Vol. 13 No. 13-14, pp. 1281-1294.

Stancu, V., Haugaard, P. and Lähteenmäki, L. (2016), "Determinants of consumer food waste behaviour: Two routes to food waste", Appetite, Vol. 96, pp. 7-17.

Statista (2017), Internet of Things (IoT) connected devices installed base worldwide from 2015 to 2025 (in billions). [Online]. Available at: https://www.statista.com/statistics/471264/iot-number-of-connecteddevices-worldwide/ (Accessed: 21-Nov-2017).

Statista (2018), Household waste in England (UK).

The Japan Electrical Manufactures' Association (2014), Report on Life Cycle Inventory (LCI) Analyses of Refrigerators.

van Loon, P., Deketele, L., Dewaele, J., McKinnon, A. and Rutherford, C. (2015), “A comparative analysis of carbon emissions from online retailing of fast moving consumer goods", Journal of Cleaner Production, Vol. 106, pp. 478-486.

Veeramani, A., Dias, G.M. and Kirkpatrick, S.I. (2017), "Carbon footprint of dietary patterns in Ontario, Canada: A case study based on actual food consumption”, Journal of cleaner production, Vol. 162, pp. 1398-1406.

Waters, L., Goodright, V. and WilNes, E. (2015), Energy Consumption in the UK (2015), Department of Energy and Climate Change.

Weber, C.L., Hendrickson, C.T., Matthews, H.S., Nagengast, A., Nealer, R. and Jaramillo, P. (2009, May), "Life cycle comparison of traditional retail and e-commerce logistics for electronic products: A case study of buy.com”, Sustainable Systems and Technology, 2009. ISSST'09. IEEE International Symposium on, IEEE, pp. 1-6.

Weideli, D. and Cheikhrouhou, N. (2013), Environmental Analysis of US Online Shopping, Doctoral dissertation, Master Thesis for MIT Center for Transportation \& Logistics, Cambridge MA, USA.

Winkler, T., Schopf, K., Aschemann, R. and Winiwarter, W. (2016), "From farm to fork-A life cycle assessment of fresh Austrian pork", Journal of Cleaner Production, Vol. 116, pp. 80-89.

Wrap (2015), Reducing the amount of food and drink that gets wasted in the home. Available at: http://www.wrap.org.uk/sites/files/wrap/Consumer_Food_Waste_Prevention_narrative_0.pdf.

Xiao, R., Zhang, Y., Liu, X. and Yuan, Z. (2015), "A life-cycle assessment of household refrigerators in China”, Journal of Cleaner Production, Vol. 95, pp. 301-310. 